\title{
A systematic review and meta-analysis of the prevalence of thrombosis and bleeding at diagnosis of Philadelphia-negative myeloproliferative neoplasms
}

Tarinee Rungjirajittranon ${ }^{1}$, Weerapat Owattanapanich ${ }^{2^{*}}$ (D), Patompong Ungprasert ${ }^{3}$, Noppadol Siritanaratkul ${ }^{2}$ and Theera Ruchutrakool ${ }^{2}$

\begin{abstract}
Background: Philadelphia (Ph) chromosome-negative myeloproliferative neoplasms (MPNs) are a heterogeneous group of hematopoietic stem cell clonal diseases. Most patients with MPN are asymptomatic at diagnosis although some of them suffer from constitutional symptoms. Thrombosis and bleeding can also be one of the initial manifestations although the reported prevalence varied considerably across the studies. This systematic review and meta-analysis was conducted with the aims to better understand the prevalence and characteristics of thrombosis and bleeding among patients with newly-diagnosed MPN.

Methods: Using a search strategy that included the terms for myeloproliferative neoplasms, thrombosis, and bleeding, two investigators independently searched for published articles indexed in the MEDLINE and EMBASE databases from inception to August 2018. The pooled prevalence was calculated using the DerSimonian-Laird random-effects model with a double arcsine transformation.

Results: A total of 29 cohort studies (8 prospective and 21 retrospective) with 13,436 patients with MPN were included into this meta-analysis. At diagnosis, the pooled prevalence of overall thrombosis among patients with MPN was $20.0 \%$ (95\% Cl, 16.6-23.8\%; $I^{2}$ 96\%), with the pooled prevalence of arterial thrombosis of $16.2 \%(95 \% \mathrm{Cl}$, $\left.13.0-20.0 \% ; 1^{2} 95 \%\right)$ and the pooled prevalence of venous thrombosis of $6.2 \%$ (95\% Cl, 4.9-7.8\%; $\left.\left.\right|^{2} 89 \%\right)$. Common thrombotic events included cerebrovascular disease/transient ischemic attack, coronary heart disease, and deep venous thrombosis. The pooled prevalence of hemorrhagic complications among patients who were newly diagnosed with MPN patients was 6.2\% (95\% Cl, 5.0-7.8\%; $\left.\left.\right|^{2} 85 \%\right)$. Common sites of bleeding included gastrointestinal, mucosal, and cutaneous bleeding.
\end{abstract}

Conclusions: Thrombosis and bleeding are common initial manifestations of MPN. Investigations for MPN should be considered for patients who present with unexplained thrombosis or abnormal bleeding.

Keywords: Myeloproliferative neoplasms, Polycythemia vera, Essential thrombocythemia, Primary myelofibrosis, Prevalence, Thrombosis, Bleeding, Hemorrhage

\footnotetext{
*Correspondence: weerapato36733@gmail.com

${ }^{2}$ Division of Hematology, Department of Medicine, Faculty of Medicine Siriraj

Hospital, Mahidol University, 2 Wanglang Road, Bangkok 10700, Thailand

Full list of author information is available at the end of the article
}

(c) The Author(s). 2019 Open Access This article is distributed under the terms of the Creative Commons Attribution 4.0 International License (http://creativecommons.org/licenses/by/4.0/), which permits unrestricted use, distribution, and reproduction in any medium, provided you give appropriate credit to the original author(s) and the source, provide a link to the Creative Commons license, and indicate if changes were made. The Creative Commons Public Domain Dedication waiver (http://creativecommons.org/publicdomain/zero/1.0/) applies to the data made available in this article, unless otherwise stated. 


\section{Background}

Philadelphia $(\mathrm{Ph})$ chromosome-negative myeloproliferative neoplasms (MPNs) are a heterogenous group of hematopoietic stem cell clonal diseases, of which the main subtypes are polycythemia vera (PV), essential thrombocythemia (ET), and primary myelofibrosis (PMF) $[1,2]$. More than a half of the patients are asymptomatic at diagnosis although some of them suffer from weight loss, fatigue, fever, pruritus, and early satiety. Thrombosis and bleeding can also be ones of the initial manifestations that eventually lead to the diagnosis of MPN [3, 4].

Thrombosis in patients with MPN could manifest as mild microcirculatory disturbance or as major arterial and venous thrombotic events such as ischemic stroke, myocardial infarction, peripheral arterial disease, and deep vein thrombosis [5]. Similarly, bleeding in these patients can be a minor one or could manifest as major internal organ hemorrhage [6]. The reported prevalence of thrombosis and bleeding among patients who were newly diagnosed with MPN varied considerably across the studies [7-35]. As one of the aims of the treatments of MPN is to decrease the risk of thrombosis and some prescribed medications, such as aspirin, can increase the risk of bleeding, knowing the baseline prevalence of thrombosis and bleeding would be of clinical importance for clinicians who need to balance the risk between these two opposite complications. The current systematic review and meta-analysis was conducted with the aims to better understand the prevalence and characteristics of thrombosis and bleeding among patients with newly-diagnosed MPN by comprehensively identifying all available studies and summarizing their results together.

\section{Methods}

\section{Data sources and searches}

Using a search strategy that included the terms for myeloproliferative neoplasms, thrombosis, and bleeding, two investigators (T.R.1 and W.O.) independently searched for published articles indexed in the MEDLINE and EMBASE databases from inception to August 2018. The search strategy is available as Additional file 1. In addition, the references of the included studies were also manually reviewed to identify additional eligible studies. This study was performed according to the Preferred Reporting Items for Systematic Reviews and Meta-Analyses statement, which is available as Additional file 2 [36].

\section{Selection criteria and data extraction}

To be eligible for inclusion into the meta-analysis, first, the study needed to consist of at least one cohort of patients who were newly diagnosed with Philadelphia negative MPNs (PV, ET, or PMF). Then, the study needed to report the overall prevalence of thrombosis and/or bleeding at diagnosis of that cohort. The secondary outcomes of interest, including prevalence of thrombosis for each MPN subtype, prevalence of thrombosis at each location, prevalence of bleeding for each MPN subtype, and prevalence of bleeding at each location, were also collected for pooled analysis but were not part of the inclusion criteria. Both investigators evaluated all studies independently. If different decisions regarding the eligibility of a study were made, the study in question was jointly reviewed by the two investigators and the final determination was reached by consensus.

\section{Statistical analysis}

Comprehensive Meta-Analysis program, version 2.2 (Biostat, Englewood, NJ, USA) was used to analyze all data. The same two authors (T.R.1 and W.O.) extracted and tabulated all data from each eligible study using a standardized data extraction form. The pooled rates and 95\% confidence intervals (CI) of the overall prevalence of thrombosis at diagnosis, overall prevalence of bleeding at diagnosis, prevalence of thrombosis at each location, prevalence of bleeding for each MPN subtype, and prevalence of bleeding at each location, were calculated using the DerSimonian-Laird random-effects model with a double arcsine transformation [37]. The random-effects model was utilized as opposed to a fixed-effects model as the between-study heterogeneity was suspected to be high due to the difference in background populations between studies. The heterogeneity was calculated using Cochran's Q test and the $\mathrm{I}^{2}$ statistic. The $\mathrm{I}^{2}$ statistic quantifies the proportion of total variation across studies; the $\mathrm{I}^{2}$ values were classified as follows: an $\mathrm{I}^{2}$ of $0-25 \%$ indicated insignificant heterogeneity; 26-50\%, low heterogeneity; 51-75\%, moderate heterogeneity; and greater than 75\%, high heterogeneity [38].

\section{Results}

A total of 6177 articles (2672 from MEDLINE and 3505 from EMBASE) were identified using the aforementioned search strategy. A total of 2306 articles were duplication between the databases, which were removed using EndNote X8 software, leaving 3871 articles for the first round of review (review of title and abstract). After the first round of review, 3754 articles were excluded because they clearly did not meet the pre-specified inclusion criteria based on type of article, study design, and study participants. A full-text review of the remaining 117 articles was undertaken and 88 articles were found to be ineligible for the meta-analysis (16 articles were reviews, meta-analysis or commentaries; 3 articles did not recruit patients with MPNs; and 69 articles did not 
report our outcome of interest). Finally, 29 cohort studies (8 prospective studies and 21 retrospective studies) were included in the meta-analysis [7-35]. The literature review and identification process are summarized as Fig. 1.

\section{Baseline patient characteristics}

A total of 13,436 patients who were newly diagnosed with MPN from 29 studies were included in this meta-analysis. ET was the most common subtype of MPN among patients analyzed in this meta-analysis (49.2\%), followed by PV (34.7\%), and PMF (14.4\%). There was a slight overall female predominance (52.4\%) while the median age of participants ranged from 42 to 76 years across the studies. The prevalence of thrombosis was reported by 26 studies while the prevalence of bleeding was reported by 21 studies. Table 1 describes the characteristics and participants of the included studies. The data on managements and clinical outcomes of participants in these studies are described in Additional file 3: Table S1.

\section{Prevalence of thrombosis at diagnosis of MPN}

At diagnosis, the pooled prevalence of overall thrombosis (either arterial or venous) among patients with MPN was $20.0 \%$ (95\% CI, 16.6-23.8\%; I ${ }^{2}$ 96\%; Fig. 2) [7-18, 20-23, 25-32, 34, 35]. The pooled prevalence for each MPN subtype was as followed; PV 28.6\% (95\% CI,
22.0-36.3\%; $\mathrm{I}^{2}$ 95\%) [10, 12, 14, 18, 19, 26, 28, 29, 31, 32], ET 20.7\% (95\% CI, 16.6-25.5\%; I ${ }^{2}$ 93\%) [7-11, 13, 16-18, $22,25,26,28,29,31,32,34]$, and PMF 9.5\% (95\% CI, 5.017.4\%; $\mathrm{I}^{2}$ 94\%) [10, 20, 21, 23, 26, 28, 29, 32] (Fig. 3). The pooled prevalence of arterial thrombosis was $16.2 \%$ (95\% CI, 13.0-20.0\%; I ${ }^{2}$ 95\%) [7-14, 17-23, 26-29, $31,32,34,35]$ while the pooled prevalence of venous thrombosis was $6.2 \%\left(95 \%\right.$ CI, $\left.4.9-7.8 \% ; \quad I^{2} \quad 89 \%\right)$ (Fig. 4) [7-14, 17-23, 26, 28, 29, 31, 32, 34, 35].

\section{Sites of arterial thrombosis}

The pooled prevalence of arterial thrombosis at diagnosis of MPN for each specific site was as followed; cerebrovascular disease $7.4 \%\left(95 \%\right.$ CI, $5.0-10.8 \%$; $\mathrm{I}^{2}$ 90\%) $[7-9,11,13,14,19,21,25-27,29]$, transient ischemic attack of 3.5\% (95\% CI, 1.9-6.4\%; $\mathrm{I}^{2}$ 91\%) [8, 9, 11, $13,19,21,25-27,35]$, coronary heart disease $6.1 \%(95 \%$ CI, 5.1-7.4\%; $\mathrm{I}^{2}$ 73\%) [7-14, 17, 19-22, 25-29, 31, 35], and peripheral arterial disease 3.3\% (95\% CI, 2.2-4.8\%; $\left.\mathrm{I}^{2} 87 \%\right)[7-9,11,13,14,17,19-22,26,28,31]$. The forest plots of each arterial thrombotic event are provided as Additional file 4.

\section{Sites of venous thrombosis}

The pooled prevalence of venous thrombosis at diagnosis of MPN for each specific site was as followed; deep vein thrombosis 3.4\% (95\% CI, 2.0-5.6\%; I ${ }^{2} 85 \%$ ) $[7-9,14,18,19,28,29,35]$, splanchnic vein thrombosis

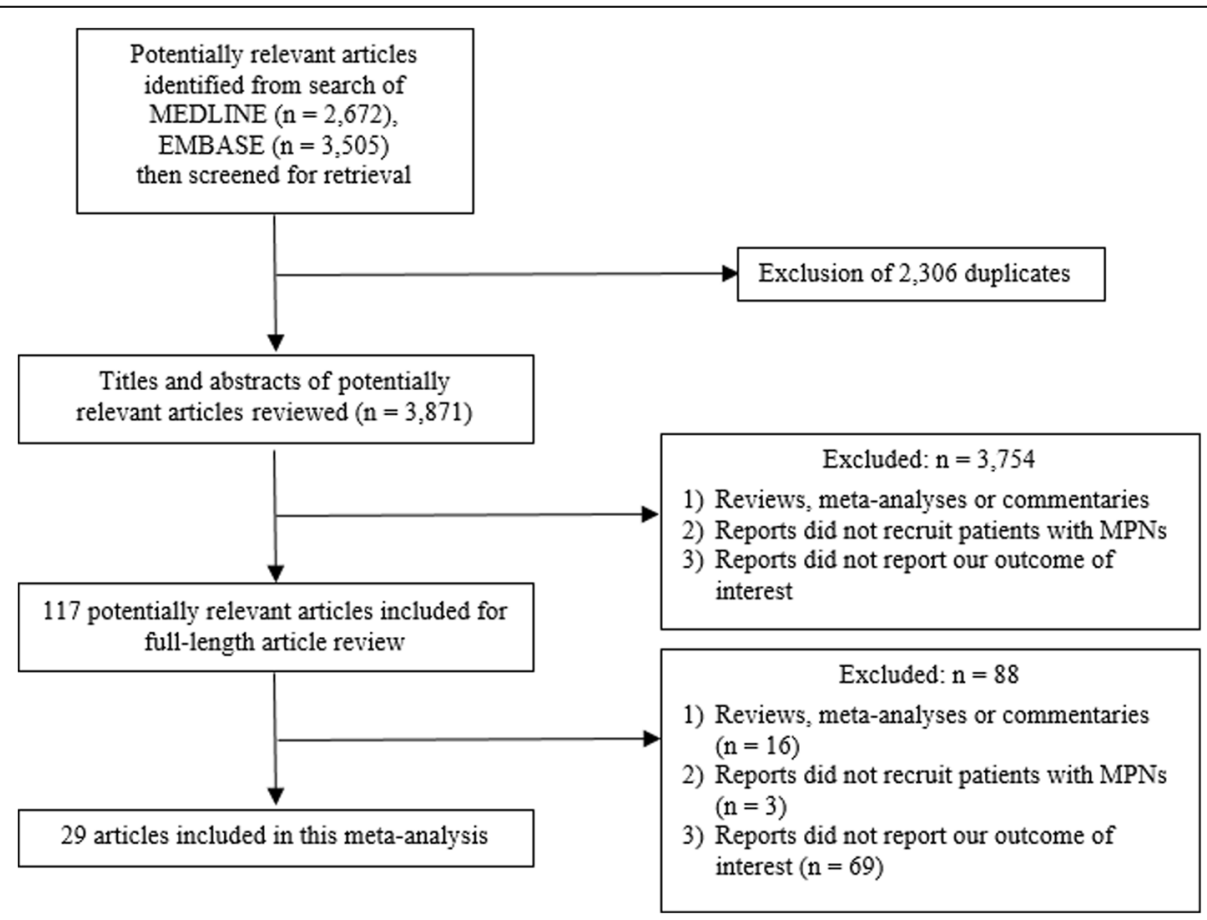

Fig. 1 Flowchart of literature review process 
Table 1 Baseline patient characteristics of the included studies

\begin{tabular}{|c|c|c|c|c|c|c|c|c|c|c|}
\hline References & No. & $\operatorname{Sex}(M / F)$ & $\begin{array}{l}\text { Median age } \\
\text { (years, range) }\end{array}$ & No. of PV & No. of ET & No. of PMF & $\begin{array}{l}\text { Thrombotic } \\
\text { outcome }\end{array}$ & $\begin{array}{l}\text { Bleeding } \\
\text { outcome }\end{array}$ & $\begin{array}{l}\text { Study } \\
\text { period }\end{array}$ & Type \\
\hline Fenaux 1990 [7] & 147 & $60 / 87$ & $60(18-83)$ & - & 147 & - & Yes $(A+V)$ & Yes & 1970-1987 & $\mathrm{R}$ \\
\hline Colombi 1991 [8] & 103 & $44 / 59$ & $59(9-88)$ & - & 103 & - & Yes $(A+V)$ & Yes & 1975-1990 & $\mathrm{R}$ \\
\hline Besses 1999 [9] & 148 & $53 / 95$ & $60.5(11-85)$ & - & 148 & - & Yes $(A+V)$ & Yes & 1979-1994 & $\mathrm{R}$ \\
\hline Manoharan 1999 [10] & 61 & $\begin{array}{l}\text { PV: } 10 / 10 \\
\text { ET: 10/ } 20 \\
\text { PMF: } 5 / 6\end{array}$ & $\begin{array}{l}\text { PV: } 76(54-84) \\
\text { ET: } 71 \text { (25-88) } \\
\text { PMF: } 74 \text { (31-84) }\end{array}$ & 20 & 30 & 11 & Yes $(A+V)$ & No & 1993-1997 & $P$ \\
\hline Jensen 2000 [11] & 96 & $27 / 69$ & $67(18-87)$ & - & 96 & - & Yes $(A+V)$ & Yes & 1977-1998 & $\mathrm{R}$ \\
\hline Passamonti 2000 [12] & 163 & $98 / 65$ & $57(30-82)$ & 163 & - & - & Yes $(A+V)$ & Yes & 1975-1997 & $\mathrm{R}$ \\
\hline Chim 2005 [13] & 231 & $112 / 119$ & 65 (18-90) & - & 231 & - & Yes $(A+V)$ & Yes & NR & $\mathrm{R}$ \\
\hline Marchioli 2005 [14] & 1638 & $942 / 696$ & 60.4 & 1638 & - & - & Yes $(A+V)$ & Yes & NR & $P$ \\
\hline Cervantes 2006 [15] & 155 & $97 / 58$ & $65(17-89)$ & - & - & 155 & Yes $(A+V)$ & No & 1972-2005 & $\mathrm{R}$ \\
\hline Wolanskyj 2006 [16] & 322 & $104 / 218$ & $54(12-88)$ & - & 322 & - & Yes $(A+V)$ & Yes & 1956-1992 & $\mathrm{R}$ \\
\hline Carobbio 2007 [17] & 439 & $175 / 264$ & $54(10-93)$ & - & 439 & - & Yes $(A+V)$ & No & 1981-2006 & $\mathrm{R}$ \\
\hline Vannucchi 2007 [18] & 962 & $\begin{array}{l}\text { PV: 176/ } 147 \\
\text { ET: 202/ } 437\end{array}$ & NR & 323 & 639 & - & Yes $(A+V)$ & No & NR & $\mathrm{R}$ \\
\hline Bang 2009 [19] & 283 & $143 / 140$ & 61 & 120 & NR & NR & Yes $(A+V)$ & Yes & 2006-2007 & $P$ \\
\hline Barbui 2010 [20] & 707 & $465 / 242$ & $62(11-90)$ & - & - & 707 & Yes $(A+V)$ & No & 1973-2008 & $\mathrm{R}$ \\
\hline Elliott 2010 [21] & 205 & $131 / 74$ & $62(28-87)$ & - & - & 205 & Yes $(A+V)$ & No & 1982-2008 & $\mathrm{R}$ \\
\hline Palandri 2011 [22] & 532 & $205 / 327$ & $64(16-95)$ & - & 532 & - & Yes $(A+V)$ & No & 1978-2008 & $\mathrm{R}$ \\
\hline Buxhofer-Ausch 2012 [23] & 264 & $109 / 155$ & 57.4 & - & - & 264 & Yes $(A+V)$ & No & NR & $P$ \\
\hline Finazzi 2012 [24] & 1104 & $\begin{array}{l}\text { ET: 370/ } 521 \\
\text { PMF: 74/ } 106\end{array}$ & $\begin{array}{l}\text { ET: } 55.7(12.9-91) \\
\text { PMF: } 57.4(20.9-87.7)\end{array}$ & - & 891 & 180 & No & Yes & NR & $P$ \\
\hline Angona 2015 [25] & 214 & $57 / 157$ & $64(9-93)$ & - & 214 & - & Yes $(A+V)$ & No & 1985-2012 & $\mathrm{R}$ \\
\hline Enblom 2015 [26] & 612 & $\begin{array}{l}\text { PV: } 131 / 118 \\
\text { ET: } 117 / 155 \\
\text { PMF: 47/ } 44\end{array}$ & $\begin{array}{l}\text { PV: } 69 \\
\text { ET: } 67 \\
\text { PMF: } 71\end{array}$ & 249 & 272 & 91 & Yes $(A+V)$ & Yes & 1995-2013 & $\mathrm{R}$ \\
\hline Lim 2015 [27] & 102 & $54 / 48$ & $64(24-87)$ & 33 & 69 & - & Yes $(A)$ & Yes & 2004-2012 & $\mathrm{R}$ \\
\hline Duangnapasatit 2015 [28] & 157 & $\begin{array}{l}\text { PV: } 46 / 22 \\
\text { ET: } 32 / 51 \\
\text { PMF: } 4 / 2\end{array}$ & $\begin{array}{l}\text { PV: } 59.6(18-88) \\
\text { ET: } 61.1(21-89) \\
\text { PMF: } 68.3 \text { (52-78) }\end{array}$ & 68 & 83 & 6 & Yes $(A+V)$ & Yes & 2003-2013 & $\mathrm{R}$ \\
\hline Kaifie 2016 [29] & 454 & $232 / 222$ & 60 & 142 & 140 & 113 & Yes $(A+V)$ & Yes & NR & $P$ \\
\hline Cerquozzi 2017 [30] & 587 & $284 / 303$ & $60(17-94)$ & 587 & - & - & Yes $(A+V)$ & No & NR & $P$ \\
\hline Abdulkarim 2017 [31] & 2389 & $\begin{array}{l}\text { PV: } 548 / 557 \\
\text { ET: } 534 / 750\end{array}$ & $\begin{array}{l}\text { PV: } 69 \text { (17-98) } \\
\text { ET: } 68 \text { (13-94) }\end{array}$ & 1105 & 1284 & - & Yes $(A+V)$ & Yes & 2008-2015 & $\mathrm{R}$ \\
\hline Soyer 2017 [32] & 708 & $\begin{array}{l}\text { PV: 132/ } 81 \\
\text { ET: 151/ } 239 \\
\text { PMF: 56/ } 49\end{array}$ & $\begin{array}{l}\text { PV: } 47.5(17-86) \\
\text { ET: } 41.5(17-89) \\
\text { PMF: } 69.5 \text { (19-87) }\end{array}$ & 213 & 390 & 105 & Yes $(A+V)$ & Yes & 1987-2014 & $\mathrm{R}$ \\
\hline Bertozzi 2017 [33] & 253 & NR & NR & 124 & 121 & 8 & Yes $(A)$ & Yes & 1978-2016 & $\mathrm{R}$ \\
\hline Zhou 2018 [34] & 150 & $67 / 83$ & $61(41-71)$ & - & 150 & - & Yes $(A+V)$ & No & 2013-2016 & $P$ \\
\hline Hintermair 2018 [35] & 250 & 152/ 98 & NR & NR & NR & $N R$ & Yes $(A+V)$ & No & 2008-2015 & $\mathrm{R}$ \\
\hline
\end{tabular}

Abbreviations: A Artery, ET Essential thrombocythemia, F Female, $M$ Male, NR Not reported, $P$ Prospectively, PMF Primary myelofibrosis, $P V$ Polycythemia vera, $R$ Retrospectively, $V$ Vein

1.4\% (95\% CI, 0.8-2.2\%; I ${ }^{2} 78 \%$ ) [12, 13, 18, 20, 21, 26, $28,29,31,35]$, pulmonary embolism (PE) $0.9 \%$ (95\% CI, $0.4-2.3 \%$; $\mathrm{I}^{2} 74 \%$ ) $[9,14,18,28,35]$, and cerebral venous sinus thrombosis $0.7 \%$ [95\% CI, $0.2-2.3 \%$; $\mathrm{I}^{2} 0 \%$ ] [21, 28]. The forest plots of each venous thrombotic event are provided as Additional file 4.
Prevalence of bleeding at diagnosis of MPN

The pooled prevalence of hemorrhagic complications among patients who were newly diagnosed with MPN patients was $6.2 \%$ (95\% CI, 5.0-7.8\%; $\mathrm{I}^{2}$ 85\%; Fig. 5) $[7-9,11-14,16,18,19,24-29,31-35]$. The pooled prevalence for each MPN subtype was as followed; 


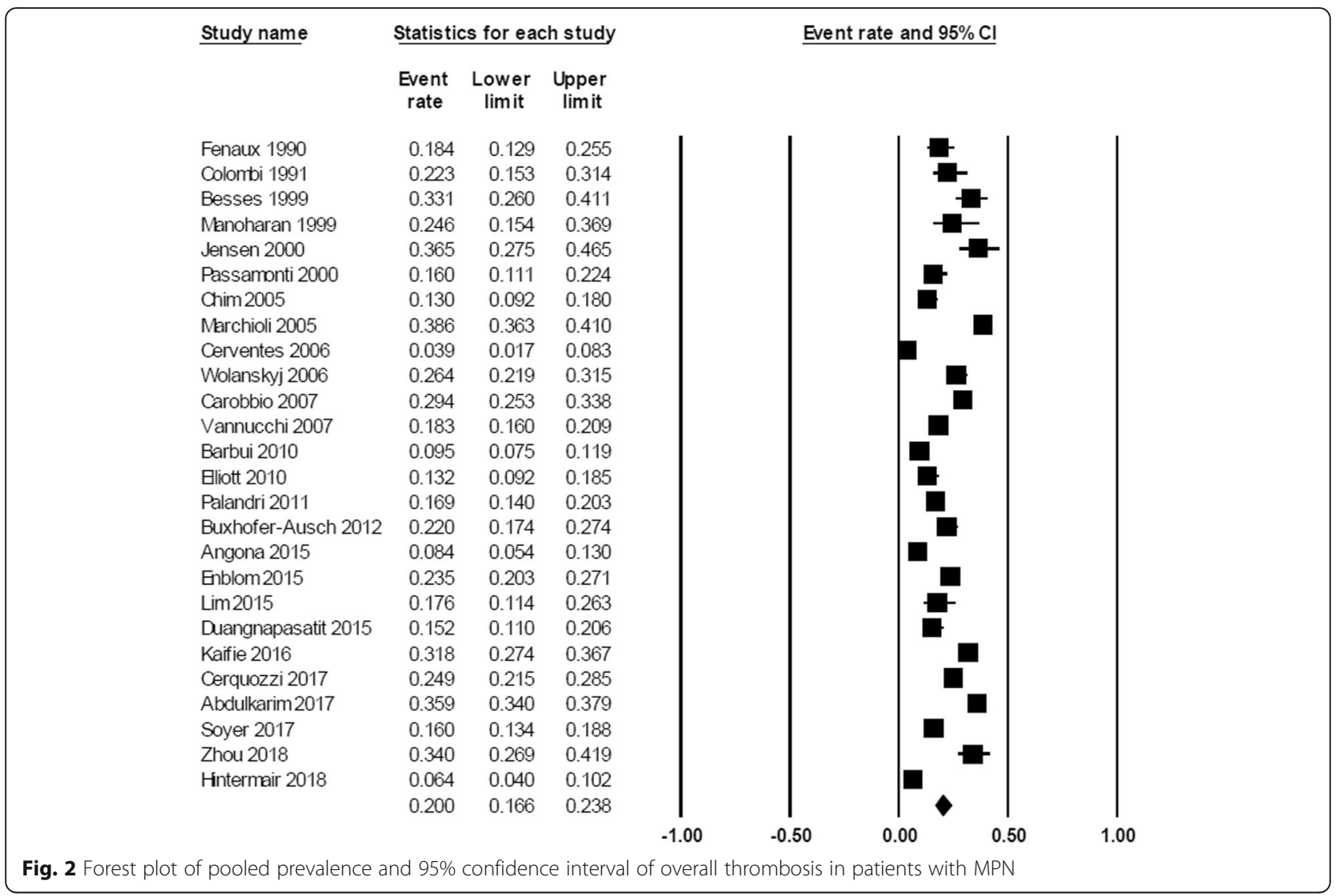

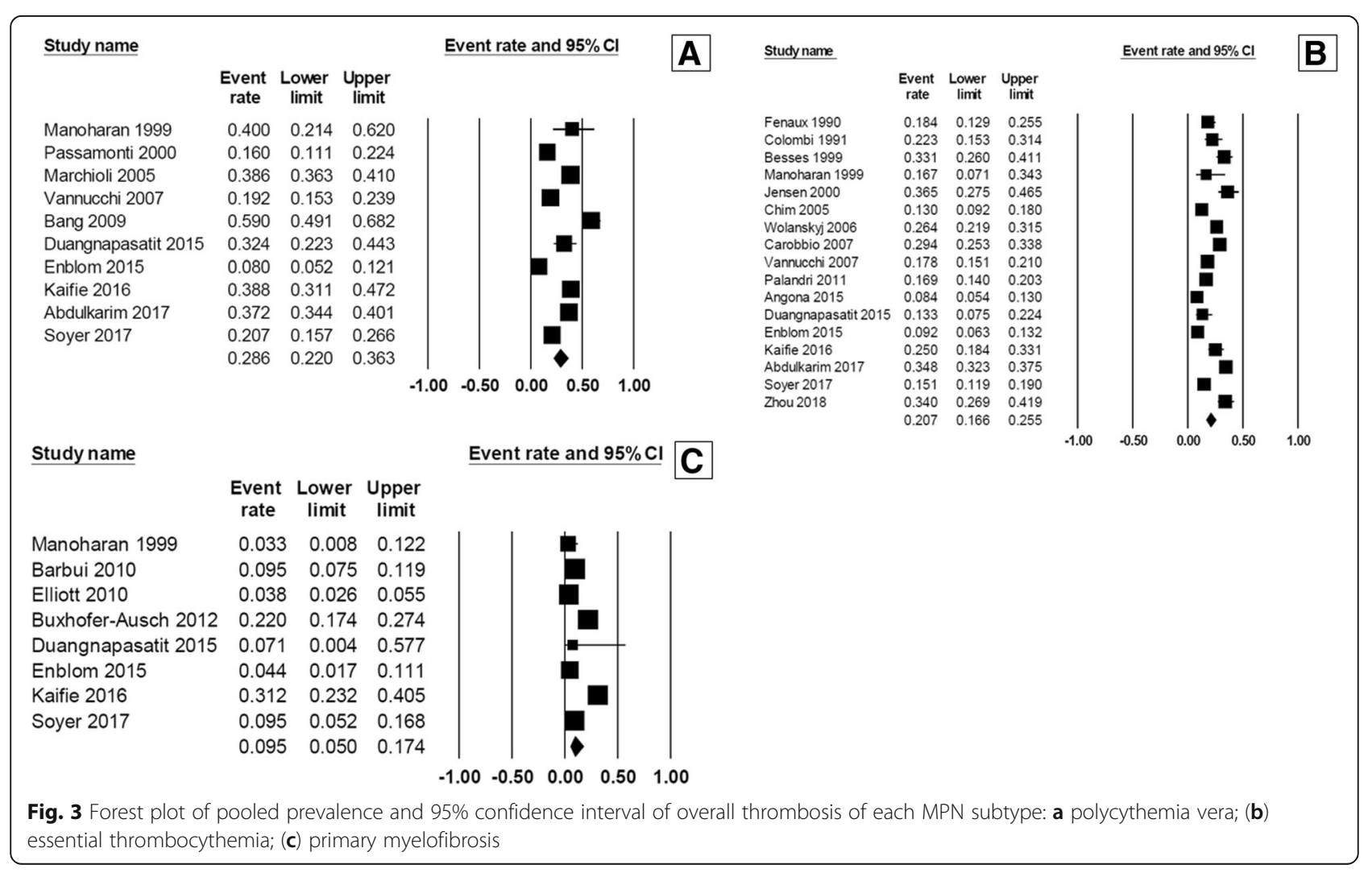




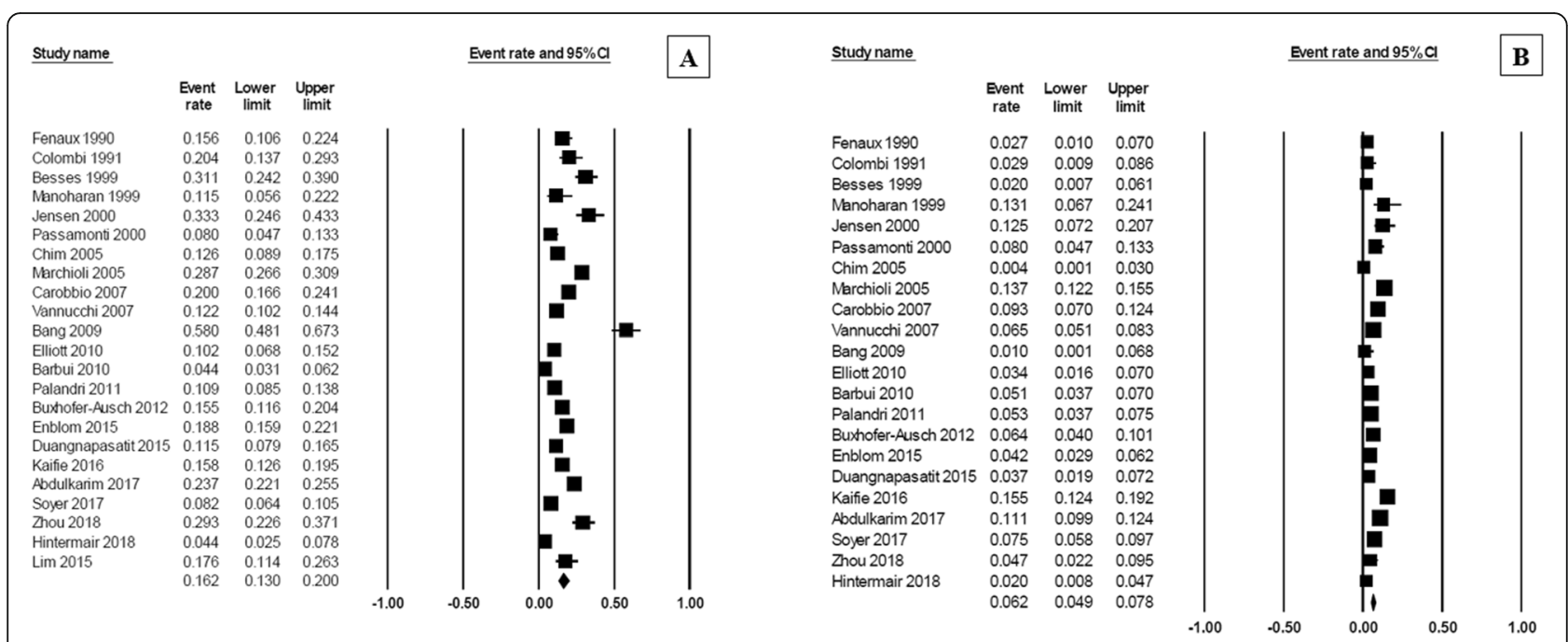

Fig. 4 Forest plot of pooled prevalence and 95\% confidence interval of (a) arterial thrombosis and (b) venous thrombosis in patients with MPN

PMF 8.9\% (95\% CI, 6.5-12.2\%; $\mathrm{I}^{2} 0 \%$ ) [24, 28, 29, 32], ET 7.3\% (95\% CI, 5.3-10.0\%; I ${ }^{2} 84 \%$ ) [7-9, 11, 13, 16, $24,28,29,31,32,34]$, and PV 6.9\% (95\% CI, 5.58.7\%; I ${ }^{2}$ 53\%) (Fig. 6) [12, 14, 28, 29, 31, 32].

Prevalence of some specific types of bleeding at the diagnosis of MPN was reported by the included studies. Their pooled prevalence was as followed; mucocutaneous bleeding 2.8\% (95\% CI, 1.4-5.8\%; $\mathrm{I}^{2} 35 \%$ ) [11, 19 , 28], gastrointestinal bleeding $2.1 \%$ (95\% CI, $1.3-3.1 \%$; $\mathrm{I}^{2}$
68\%) $[7,8,11,13,24,26,28,29,31,35]$, epistaxis $1.0 \%$ (95\% CI, $\left.0.5-2.0 \% ; \mathrm{I}^{2} 0 \%\right)[8,11,26]$, and postoperative bleeding $1.1 \%$ (95\% CI, $0.5-2.1 \%$; I ${ }^{2} 0 \%$ ) [8, 11, 28, 29]. The forest plots of each specific type of bleeding are provided as Additional file 5.

\section{Discussion}

The current study is the first systematic review and meta-analysis to evaluate the frequency of thrombotic

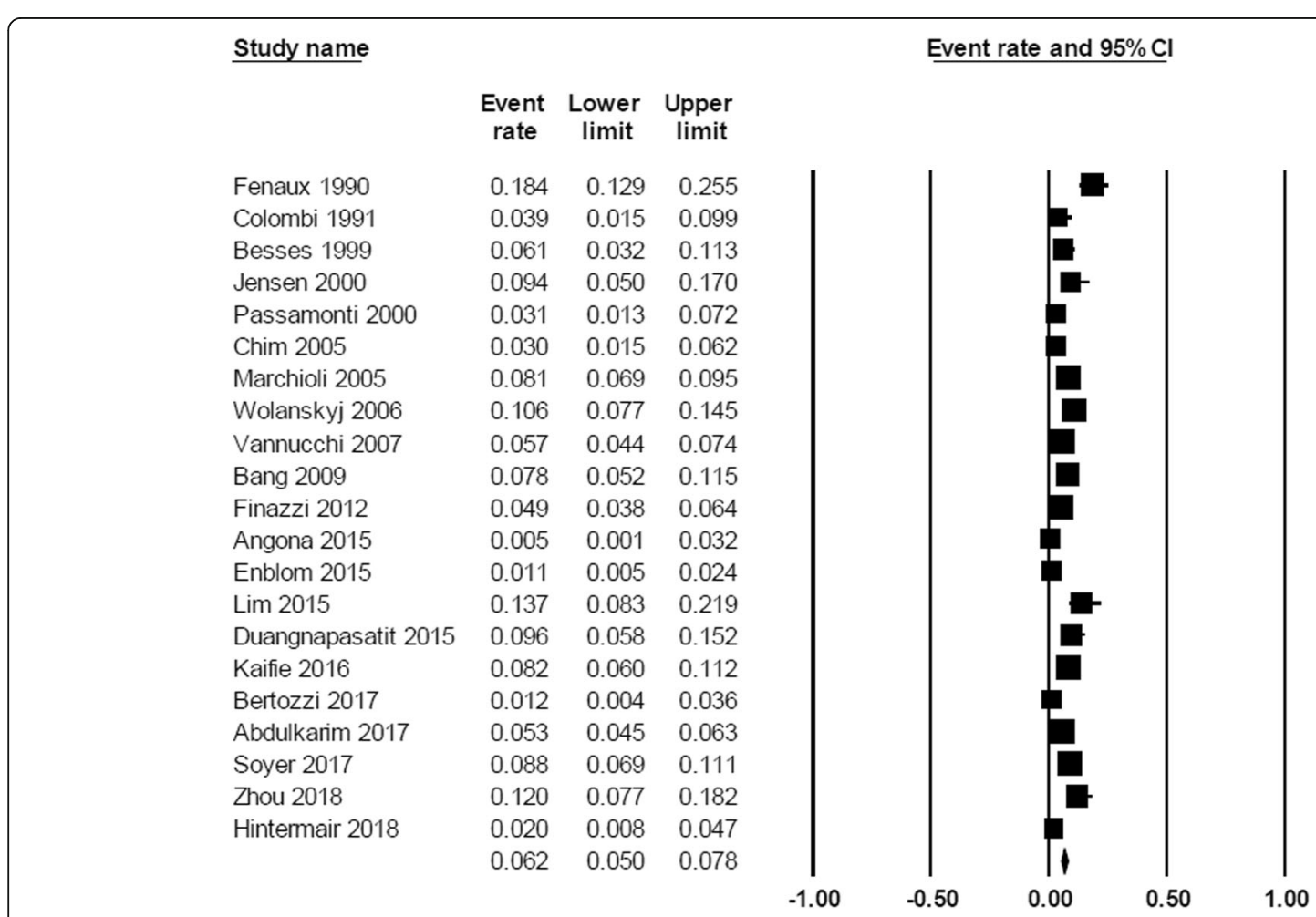

Fig. 5 Forest plot of pooled prevalence and $95 \%$ confidence interval of overall bleeding complications in patients with MPN 


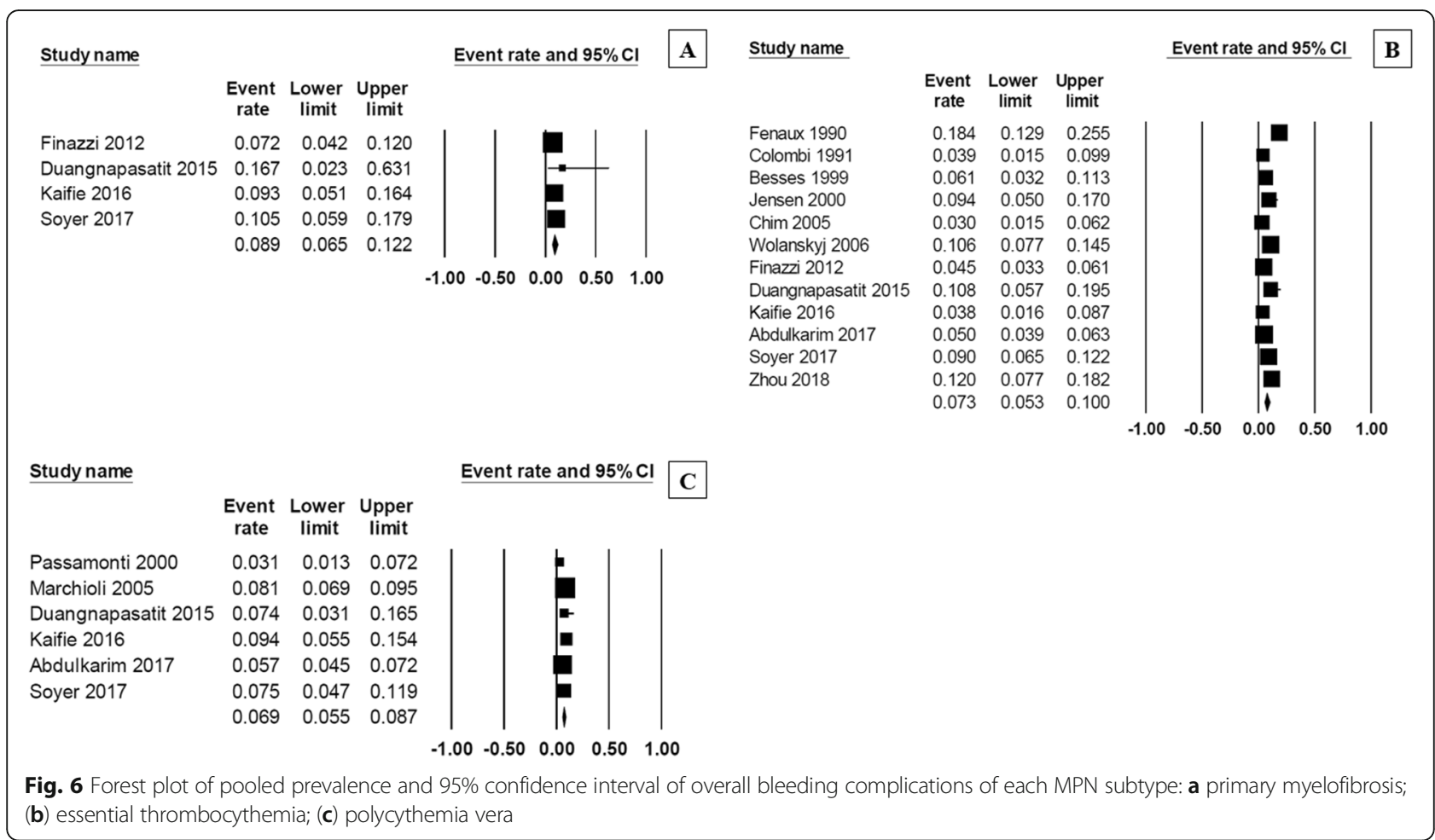

and hemorrhagic events as the initial manifestations of MPN. We found the pooled prevalence of thrombosis at diagnosis of MPN of $20 \%$ although the prevalence from individual study varied considerably, ranging from 9.5 to $38.6 \%$. Thrombosis could be on either arterial or venous site and appeared to be more common among patients who were newly diagnosed with PV than ET and PMF. The pathogenesis of acquired thrombophilic state in these patients is probably multifactorial in nature. Two main mechanisms have been proposed. One involves abnormalities of platelets, leukocytes, and red blood cells arising from the clonal hematopoietic cell proliferation. These abnormal cells interact and activate coagulation pathway more often than normal cells, leading to chronic activation of the coagulation cascade. Another postulated mechanism involves the chronic inflammatory state of MPN as studies have demonstrated that inflammatory cytokines can cross-activate coagulation factors and inhibit fibrinolytic pathway. In addition, those cytokines and reactive oxygen species are known to post deleterious effect on vascular endothelial cells, resulting in vascular injury. Both would serve as the fundamental factors for increased clotting tendency [39-41].

On the other hand, a high prevalence of hemorrhage at diagnosis was also observed in patients with MPN, although lower than the prevalence of thrombosis. The pathogenesis of hemorrhagic complications among patients with MPN is also probably multifactorial but it is believed that acquired von Willebrand disease from excessive binding of von Willebrand factor with the abnormal platelets and increased von Willebrand factor proteolysis is the most likely major player [42, 43]. In fact, the pattern of bleeding among patients with MPN, including gastrointestinal, mucosal, and cutaneous bleeding, is quite similar to von Willebrand disease [44]. Other possible contributing factors include thrombocytopenia from bone marrow failure associated with advance disease and secondary hemostatic defects from liver impairment due to liver fibrosis and extramedullary hematopoiesis associated with PMF [42].

The high frequency of both thrombotic and hemorrhagic events among patients with MPN demonstrated by this study has some clinical implications. First, both thrombosis and bleeding are common initial manifestations of MPN. Therefore, investigations for MPN may be warranted for patients who present with unexplained thrombosis or abnormal bleeding. Second, patients with MPN should be considered as those at higher risk of thrombotic complication and, therefore, prophylaxis with anti-platelet and/or anti-coagulation may provide benefit. Nonetheless, these patients are also at a higher risk of hemorrhagic complication and the potential benefit of thrombotic prophylaxis needs to be balanced with the bleeding risk especially in patient with extreme thrombocytosis. Further studies are still needed before the final recommendations can be made. 
There are some limitations in this study. First, it is a meta-analysis of descriptive studies that reported the prevalence of thrombosis and bleeding among patients with MPN. There were no subjects without MPN to serve as controls and, therefore, this study could not provide the information on the magnitude of the risk relative to general population. Second, between-study heterogeneity was high in most analyses which was probably due to the fact that the included studies were conducted over the time span of the past three decades and the diagnostic criteria for each MPN subtype have evolved during that time. To illustrate, based on the 2001 World Health Organization (WHO) classification of MPNs, hemoglobin level $>18.5 \mathrm{~g} / \mathrm{dL}$ in man and $>$ $16.5 \mathrm{~g} / \mathrm{dL}$ in woman were the criteria for the diagnosis of PV and one of criteria for the diagnosis of ET was platelet count $\geq 600 \times 10^{9} / \mathrm{L}$ [45]. However, the cut-offs for diagnosis of PV and ET in the 2016 WHO classification of MPNs were lowered to the hemoglobin levels of $>16.5 \mathrm{~g} / \mathrm{dL}$ in man and $>16 \mathrm{~g} / \mathrm{dL}$ in woman and platelet count of $\geq 450 \times 10^{9} / \mathrm{L}$, respectively [2] Therefore, some cases of PV and ET could have been missed by the previous classification criteria. As a result, it is likely that the characteristics of the diseases are different between the older and newer studies, even though they are labeled with the same name. It is also likely that the differences in the technology used to identify thrombosis and bleeding among these patients during the period would have affected the prevalence.

\section{Conclusions}

Thrombosis and bleeding are common initial manifestations of MPN. Investigations for MPN should be considered for patients who present with unexplained thrombosis or abnormal bleeding.

\section{Additional files}

Additional file 1: Search strategy. (DOCX $15 \mathrm{~kb}$ )

Additional file 2: The Preferred Reporting Items for Systematic Reviews and Meta-Analyses statement. (DOC $63 \mathrm{~kb}$ )

Additional file 3: Table S1. Managements and clinical outcomes of each included study. (DOCX $20 \mathrm{~kb}$ )

Additional file 4: Forest plots of pooled prevalence and 95\% confidence interval of each type of thrombosis in the patients with MPN. (DOCX 1022 kb)

Additional file 5: Forest plot of pooled prevalence and 95\% confidence interval of each type of bleeding in the patients with MPN. (DOCX $441 \mathrm{~kb}$ )

\section{Abbreviations}

ET: Essential thrombocythemia; MPNs: Myeloproliferative neoplasms; PE: Pulmonary embolism; PMF: Primary myelofibrosis; PV: Polycythemia vera; WHO: World Health Organization

\section{Acknowledgements}

Not applicable.

Funding

This was an unfunded study.

\section{Availability of data and materials}

The datasets used and/or analyzed during the current study are available from the corresponding author on reasonable request.

\section{Authors' contributions}

All authors designed the study. TR1 and WO manually reviewed the potential articles, selected the included studies, collected the data, and drafted the manuscript. P.U. performed the statistical analyses. NS, TR2, and PU made critical revisions to the manuscript. TR1 and WO revised the final manuscript. All authors read and approved the final manuscript.

Ethics approval and consent to participate

The need for ethics approval by an institutional board review was waived as this study does not directly involve human subjects.

Consent for publication

Not applicable because this study does not directly involve human subjects.

\section{Competing interests}

The authors declare that they have no competing interest.

\section{Publisher's Note}

Springer Nature remains neutral with regard to jurisdictional claims in published maps and institutional affiliations.

\section{Author details \\ ${ }^{1}$ Division of Medicine, Phranangklao Hospital, Nonthaburi 11000, Thailand. ${ }^{2}$ Division of Hematology, Department of Medicine, Faculty of Medicine Siriraj Hospital, Mahidol University, 2 Wanglang Road, Bangkok 10700, Thailand. ${ }^{3}$ Clinical Epidemiology Unit, Department of Research and Development, Faculty of Medicine Siriraj Hospital, Mahidol University, Bangkok 10700, Thailand.}

Received: 1 October 2018 Accepted: 19 February 2019

Published online: 28 February 2019

\section{References}

1. Spivak JL. Myeloproliferative neoplasms. N Engl J Med. 2017;376(22):2168-81.

2. Arber DA, Orazi A, Hasserjian R, Thiele J, Borowitz MJ, Le Beau MM, et al. The 2016 revision to the World Health Organization classification of myeloid neoplasms and acute leukemia. Blood. 2016;127(20):2391-405.

3. Kc D, Falchi L, Verstovsek S. The underappreciated risk of thrombosis and bleeding in patients with myelofibrosis: a review. Ann Hematol. 2017;96(10):1595-604.

4. Tefferi A, Guglielmelli P, Larson DR, Finke C, Wassie EA, Pieri L, et al. Longterm survival and blast transformation in molecularly annotated essential thrombocythemia, polycythemia vera, and myelofibrosis. Blood. 2014; 124(16):2507-13 quiz 615

5. Falanga A, Marchetti M. Thrombotic disease in the myeloproliferative neoplasms. Hematol Am Soc Hematol Educ Program. 2012;2012:571-81.

6. Martin K. Risk factors for and management of MPN-associated bleeding and thrombosis. Curr Hematol Malignancy Rep. 2017;12(5):389-96.

7. Fenaux P, Simon M, Caulier MT, Lai JL, Goudemand J, Bauters F. Clinical course of essential thrombocythemia in 147 cases. Cancer. 1990;66(3):549-56.

8. Colombi M, Radaelli F, Zocchi L, Maiolo AT. Thrombotic and hemorrhagic complications in essential thrombocythemia: a retrospective study of 103 patients. Cancer. 1991;67(11):2926-30.

9. Besses C, Cervantes F, Pereira A, Florensa L, Sole F, Hernandez-Boluda JC, et al. Major vascular complications in essential thrombocythemia: a study of the predictive factors in a series of 148 patients. Leukemia. 1999;13(2):150-4.

10. Manoharan A, Gemmell R, Brighton T, Dunkley S, Lopez K, Kyle P. Thrombosis and bleeding in myeloproliferative disorders: identification of at-risk patients with whole blood platelet aggregation studies. $\mathrm{Br} J$ Haematol. 1999;105(3):618-25. 
11. Jensen MK, de Nully BP, Nielsen OJ, Hasselbalch HC. Incidence, clinical features and outcome of essential thrombocythaemia in a well defined geographical area. Eur J Haematol. 2000;65(2):132-9.

12. Passamonti F, Brusamolino E, Lazzarino M, Barate C, Klersy C, Orlandi E, et al. Efficacy of pipobroman in the treatment of polycythemia vera: long-term results in 163 patients. Haematologica. 2000;85(10):1011-8.

13. Chim CS, Kwong YL, Lie AK, Ma SK, Chan CC, Wong LG, et al. Long-term outcome of 231 patients with essential thrombocythemia: prognostic factors for thrombosis, bleeding, myelofibrosis, and leukemia. Arch Intern Med. 2005;165(22):2651-8.

14. Marchioli R, Finazzi G, Landolfi R, Kutti J, Gisslinger H, Patrono C, et al. Vascular and neoplastic risk in a large cohort of patients with polycythemia vera. J Clin Oncol. 2005;23(10):2224-32.

15. Cervantes F, Alvarez-Larran A, Arellano-Rodrigo E, Granell M, Domingo A, Montserrat E. Frequency and risk factors for thrombosis in idiopathic myelofibrosis: analysis in a series of 155 patients from a single institution. Leukemia. 2006:20(1):55-60.

16. Wolanskyj AP, Schwager SM, McClure RF, Larson DR, Tefferi A. Essentia thrombocythemia beyond the first decade: life expectancy, long-term complication rates, and prognostic factors. Mayo Clin Proc. 2006:81(2):159-66.

17. Carobbio A, Finazzi G, Guerini V, Spinelli O, Delaini F, Marchioli R, et al. Leukocytosis is a risk factor for thrombosis in essential thrombocythemia: interaction with treatment, standard risk factors, and Jak2 mutation status. Blood. 2007;109(6):2310-3.

18. Vannucchi AM, Antonioli E, Guglielmelli P, Rambaldi A, Barosi G, Marchioli R, et al. Clinical profile of homozygous JAK2 617V>F mutation in patients with polycythemia vera or essential thrombocythemia. Blood. 2007;110(3):840-6.

19. Bang SM, Lee JS, Ahn JY, Lee JH, Hyun MS, Kim BS, et al. Vascular events in Korean patients with myeloproliferative neoplasms and their relationship to JAK2 mutation. Thromb Haemost. 2009;101(3):547-51.

20. Barbui T, Carobbio A, Cervantes F, Vannucchi AM, Guglielmelli P, Antonioli E, et al. Thrombosis in primary myelofibrosis: incidence and risk factors. Blood. 2010;115(4):778-82.

21. Elliott MA, Pardanani A, Lasho TL, Schwager SM, Tefferi A. Thrombosis in myelofibrosis: prior thrombosis is the only predictive factor and most venous events are provoked. Haematologica. 2010;95(10):1788-91.

22. Palandri F, Polverelli N, Catani L, Ottaviani E, Baccarani M, Vianelli N. Impact of leukocytosis on thrombotic risk and survival in 532 patients with essential thrombocythemia: a retrospective study. Ann Hematol. 2011;90(8):933-8.

23. Buxhofer-Ausch V, Gisslinger H, Thiele J, Gisslinger B, Kvasnicka HM, Mullauer $L$, et al. Leukocytosis as an important risk factor for arterial thrombosis in WHO-defined early/prefibrotic myelofibrosis: an international study of 264 patients. Am J Hematol. 2012;87(7):669-72.

24. Finazzi G, Carobbio A, Thiele J, Passamonti F, Rumi E, Ruggeri M, et al. Incidence and risk factors for bleeding in 1104 patients with essential thrombocythemia or prefibrotic myelofibrosis diagnosed according to the 2008 WHO criteria. Leukemia. 2012;26(4):716-9.

25. Angona A, Alvarez-Larran A, Bellosillo B, Martinez-Aviles L, Garcia-Pallarols F, Longaron R, et al. Essential thrombocythemia: baseline characteristics and risk factors for survival and thrombosis in a series of 214 patients. Med Clin (Barc). 2015;144(6):247-53.

26. Enblom A, Lindskog E, Hasselbalch H, Hersby D, Bak M, Tetu J, et al. High rate of abnormal blood values and vascular complications before diagnosis of myeloproliferative neoplasms. Eur J Intern Med. 2015;26(5):344-7.

27. Lim Y, Lee JO, Kim SH, Kim JW, Kim YJ, Lee KW, et al. Prediction of thrombotic and hemorrhagic events during polycythemia vera or essential thrombocythemia based on leukocyte burden. Thromb Res. 2015:135(5):846-51.

28. Duangnapasatit B, Rattarittamrong E, Rattanathammethee T, Hantrakool S, Chai-Adisaksopha C, Tantiworawit A, et al. Clinical manifestations and risk factors for complications of Philadelphia chromosome-negative myeloproliferative neoplasms. Asian Pac J Cancer Prev. 2015;16(12):5013-8

29. Kaifie A, Kirschner M, Wolf D, Maintz C, Hanel M, Gattermann N, et al. Bleeding, thrombosis, and anticoagulation in myeloproliferative neoplasms (MPN): analysis from the German SAL-MPN-registry. J Hematol Oncol. 2016;9:18.

30. Cerquozzi S, Barraco D, Lasho T, Finke C, Hanson CA, Ketterling RP, et al. Risk factors for arterial versus venous thrombosis in polycythemia vera: a single center experience in 587 patients. Blood Cancer J. 2017:7(12):662.
31. Abdulkarim K, Samuelsson J, Johansson P, Andreasson B. Risk factors for vascular complications and treatment patterns at diagnosis of 2389 PV and ET patients: real-world data from the Swedish MPN registry. Eur J Haematol. 2017:98(6):577-83.

32. Soyer N, Haznedaroglu IC, Comert M, Cekdemir D, Yilmaz M, Unal A, et al. Multicenter retrospective analysis of Turkish patients with chronic myeloproliferative neoplasms. Turk J Haematol. 2017;34(1):27-33.

33. Bertozzi I, Bogoni G, Biagetti G, Duner E, Lombardi AM, Fabris F, et al. Thromboses and hemorrhages are common in MPN patients with high JAK2V617F allele burden. Ann Hematol. 2017;96(8):1297-302.

34. Zhou D, Chen W, Cheng H, Qiao JL, Zhu LL, Li ZY, et al. Clinicohematological profile and thrombotic/hemorrhagic events in 150 chinese patients with essential thrombocythemia. Leuk Res. 2018;69:1-6.

35. Hintermair S, Zwickl-Traxler E, Pecherstorfer M, Singer J. Evaluation of vascular events in patients with myeloproliferative syndromes and mutations of either the januskinase-2 or calreticulin gene at the university hospital Krems from 2008 to 2015. Oncotarget. 2018;9(9):8450-62.

36. Moher D, Liberati A, Tetzlaff J, Altman DG. Preferred reporting items for systematic reviews and meta-analyses: the PRISMA statement. BMJ. 2009:339:2535.

37. Mathes T, Kuss O. A comparison of methods for meta-analysis of a small number of studies with binary outcomes. Res Synth Methods. 2018:9:1-16.

38. Higgins JP, Thompson SG, Deeks JJ, Altman DG. Measuring inconsistency in meta-analyses. BMJ. 2003;327(7414):557-60.

39. Xu J, Lupu F, Esmon CT. Inflammation, innate immunity and blood coagulation. Hamostaseologie. 2010;30(1):5-6 8-9.

40. Vazquez-Garza E, Jerjes-Sanchez C, Navarrete A, Joya-Harrison J, Rodriguez D. Venous thromboembolism: thrombosis, inflammation, and immunothrombosis for clinicians. J Thromb Thrombolysis. 2017;44(3):377-85.

41. Falanga A, Marchetti M. Thrombosis in myeloproliferative neoplasms. Semin Thromb Hemost. 2014;40(3):348-58,

42. Appelmann I, Kreher S, Parmentier S, Wolf HH, Bisping G, Kirschner M, et al. Diagnosis, prevention, and management of bleeding episodes in Philadelphia-negative myeloproliferative neoplasms: recommendations by the hemostasis working Party of the German Society of hematology and medical oncology $(\mathrm{DGHO})$ and the Society of Thrombosis and Hemostasis Research (GTH). Ann Hematol. 2016;95(5):707-18.

43. Budde U, Dent JA, Berkowitz SD, Ruggeri ZM, Zimmerman TS. Subunit composition of plasma von Willebrand factor in patients with the myeloproliferative syndrome. Blood. 1986;68(6):1213-7.

44. Keesler DA, Flood VH. Current issues in diagnosis and treatment of von Willebrand disease. Res Pract Thromb Haemost. 2018:2(1):34-41.

45. Vardiman JW. Myelodysplastic syndromes, chronic myeloproliferative diseases, and myelodysplastic/myeloproliferative diseases. Semin Diagn Pathol. 2003;20(3):154-79.

\section{Ready to submit your research? Choose BMC and benefit from:}

- fast, convenient online submission

- thorough peer review by experienced researchers in your field

- rapid publication on acceptance

- support for research data, including large and complex data types

- gold Open Access which fosters wider collaboration and increased citations

- maximum visibility for your research: over $100 \mathrm{M}$ website views per year

At $\mathrm{BMC}$, research is always in progress.

Learn more biomedcentral.com/submissions 